\title{
Androgenetik Alopesi
}

\section{Gökhan ŞAHİN, Hilal ÖZDEMİR, Fatma AYDIN}

Ondokuz Mayıs Üniversitesi Tıp Fakültesi, Dermatoloji Anabilim Dalı, Samsun.

\section{ÖZET}

Androgenetik alopesi genetik yatkınlığı olan kişilerde farklı patolojik mekanizmalarla ortaya çıkabilen, erkek ve kadınlarda kliniği değişiklik gösterebilen bir saç dökülme şeklidir. Androgenetik alopesi her ne kadar sık görülüyor ve tanısı genellikle kolay koyuluyor olsa da hasta yönetimi için standart bir tedavi rehberi yoktur. Androgenetik alopesi yönetiminde amaç foliküler minyatürizasyonu durdurmak ve saç dansitesini arttırmaktır. Androgenetik alopesi yönetiminde kullanılan tedaviler potasyum iyon kanalı düzenleyicileri (topikal minoksidil ve oral minoksidil), $5 \alpha$ redüktaz inhibitörleri (oral finasterid, topikal finasterid ve oral dutasterid), androjen reseptör antagonistleri (spironolakton, siproteron asetat, flutamid, korteksolon 17 alfa propionat ve topikal fluridil), diğer medikal tedaviler (topikal prostoglandin analogları, topikal ketokonazol, topikal melatonin, Wnt/ $\beta$ katenin sinyal yolağı aktivatörleri ve JAK-STAT yolağı inhibitörleri), fiziksel tedaviler (düşük dereceli lazer ışık tedavisi, lazer tedavileri, mikroiğneleme, mezoterapi, PRP ve kök hücre tedavileri), tamamlayıcı tedaviler (saç transplantasyonu, besin takviyeleri ve kamuflaj yöntemleri) ve kombinasyon tedavileridir. Bu derlemede erkek ve kadında androgenetik alopesi yönetiminde güncel tedavi yöntemleri hakkında bilgi verilmesi amaçlanmıştır.

Anahtar Kelimeler: Androgenetik alopesi. Patogenez. Hasta yönetimi. Minoksidil. Finasterid.

\section{Androgenetic Alopecia}

\section{ABSTRACT}

Androgenetic alopecia is a form of hair loss that can occur with different pathological mechanisms in people with genetic predisposition, and the clinic may vary in men and women. Although androgenetic alopecia is common and its diagnosis is usually easy, there is no standard treatment guideline for patient management. The purpose of the management of androgenetic alopecia is to stop follicular miniaturization and to increase hair density. Therapies used in the management of androgenetic alopecia are potassium ion channel modifiers (topical minoxidil and oral minoxidil), $5 \alpha$ reductase inhibitors (oral finasteride, topical finasteride and oral dutasteride), androgen receptor antagonists (spironolactone, cyproterone acetate, flutamide, cortexolone 17 alpha propionate solution and topical minoxidil), other medical treatments (topical prostaglandin analogues, topical ketoconazole, topical melatonin, Wnt / $\beta$ catenin signaling pathway activators and JAK-STAT pathway inhibitors), physical treatments (low-grade laser light therapy, laser treatments, microneedling, mesotherapy, PRP and stem cell treatments), complementary therapies (hair transplantation, nutritional supplements and camouflage methods) and combination therapies. In this review, it is aimed to provide information about current treatment methods in the management of androgenetic alopecia in men and women.

Key Words: Androgenetic alopecia. Pathogenesis. Patient management. Minoxidil. Finasteride.

Androgenetik alopesi (AGA); genetik yatkınlığı bulunan kişilerde farklı mekanizmalarla ortaya çıkan, yaşla birlikte sıklığı ve şiddeti artan, kadın ve erkeklerde farklı karakteristik dökülme paterni tanımlanmış olan

Geliş Tarihi: 11.Ocak.2021

Kabul Tarihi: 31.Mart.2021

Dr. Gökhan ŞAHIN

Ondokuz Mayıs Üniversitesi Tıp Fakültesi,

Dermatoloji Anabilim Dalı,

Samsun.

Tel: 05054457727

E-posta: sgokhan55@hotmail.com

Yazarların ORCID ID Bilgisi:

Gökhan ŞAHIN: 0000-0002-7129-4339

Hilal ÖZDEMIR: 0000-0003-0958-2767

Fatma AYDIN: 0000-0002-5176-249X bir saç kayb1 tipidir. Androgenetik alopesiyi patogenezi, klinik özellikleri ve tedavi yönetimi farklılık gösterebileceği için erkek tipi AGA ve kadın tipi AGA olarak değerlendirmek daha doğrudur. Erkeklerde saçlı deride frontal, verteks ve bazen de temporal bölgedeki saçlar dökülürken; kadınlarda genellikle frontal saç çizgisi korunur, frontal ve verteks bölgesinde saç dökülmesi görülür.

\section{Epidemiyoloji}

Androgenetik alopesi sıklığı yaşa, cinsiyete ve ırka göre farkl1lık gösterebilmektedir. AGA görülme sıkl1ğ 1 yaş ile birlikte artış gösterir. Bir çalışmada ortaşiddetli saç kayıplarının (Hamilton-Norwood sınıflandırması III ve fazlası) görülme sıklığı 18-29 yaş arası 
erkeklerde \%16, 40-49 yaş arası erkeklerde \%53 olarak bildirilmiştir ${ }^{1}$. AGA'nın görülme sıklığı kadınlarda erkeklere göre daha azdır. Başka bir çalışmada kadın tipi AGA'nın 20-29 yaş arasında görülme sıklığ $\% 3$; 40-49 yaş arasında \%16 olduğu aktarılmıştır². Asya 1rkında, Kafkas ırkına göre AGA görülme sıklığ daha azdır. Bir çalışmada Korelilerde androgenetik alopesi sıklığı erkeklerde 3. dekatta \%2,3, 5. dekatta $\% 10,8$; kadınlarda ise 3 . dekatta $\% 0,2,5$. dekatta $\% 3,8$ olduğu gösterilmiştir ${ }^{3}$.

\section{Patogenez}

Androgenetik alopeside temel sorun anagen fazın kısalması ve terminal kılların vellüs tipi kıllara dönüşmesidir.

Androgenetik alopeside özellikle genetik yatkınlığın yeri üzerinde durulmaktadır. Moleküler genetik çalışmalar androjen reseptörleri, histon deasetilazlar ve WNT molekülünü kodlayan genlerin androgenetik alopesi ile ilişkili olduğunu düşündürmektedir ${ }^{4}$. Androgenetik alopesi ile ilgili açıklanamamış daha birçok gen olduğu varsayılmaktadır. Androgenetik alopesi prepubertal çocuklarda da nadir de olsa görülebilir. 610 yaş arası $12 \mathrm{k} 1 \mathrm{z}$ ve 8 erkek adrogenetik alopesisi olan hastalarda yapılan bir çalışmada ailesel yatkınlığın rolü güçlü bir şekilde gösterilirken hastaların seks hormonu düzeylerinin normal aralıkta olduğu görülmüştür ${ }^{5}$.

Erkeklerde AGA oluşmasından sorumlu androjeninin dihidrotestesteron hormonu olduğu düşünülmektedir. Testesteron $5 \alpha$-redüktaz enzimi ile dihidrotestesterona dönüştürülür. Dihidrotestesteronun testesterona göre androjen reseptörlerine afinitesi daha fazladır. $5 \alpha-$ redüktaz enziminin 3 izoenzimi vardır. Özellikle tip 2 $5 \alpha$-redüktaz enziminin erkek tipi AGA ile ilişkili olduğu düşünülmektedir. Tip $25 \alpha$-redüktaz enzimi kafa derisi, sakal, gögüs folikülleri ile karaciğer ve prostatta baskındır ${ }^{6}$. Bu enzimin yokluğunda AGA gelişmemesi AGA etiyopatogenezindeki rolünü desteklemektedir $^{7}$. Yapılan bir çalışmada saçlı deride frontal bölgede, occipital bölgeye göre androjen reseptörü, $5 \alpha$ redüktaz tip 1 ve 2 izoenzimleri yoğunluklarının daha fazla olduğu, occipital bölgede ise frontal bölgeye göre sitokrom p450 aromataz (androjenlerin östrojenlere dönüşümünü sağlayan enzim) enziminin daha yoğun olduğu gösterilmiştir ${ }^{8}$. Androgenetik alopeside dihidrotestesteron hücresel düzeyde androjen reseptörüne bağlanır, hormon reseptör kompleksi anagen fazın kısalmasından sorumlu olan genleri aktive eder ${ }^{9}$. Bu durumun foliküler minyatürizasyona neden olduğu düşünülmektedir.

Bir çalışmada AGA tanılı erkeklerin saçlı derisinden alınan biyopside PGD2 (prostoglandin D2) sentetaz enzimini kodlayan genin ekspresyonunda artış tespit edilmiştir ${ }^{10}$. PGD2 sentetaz enzimi PGH2'yi PGD2'ye çevirmektedir. PGD2'nin kıl büyümesini inhibe ettiği gösterilmiştir.
Erkek tipi AGA'da olduğu gibi kadın tipi AGA'nın patogenezinde de androjenlerin ve genetik yatkınlığın rolü üzerinde durulmaktadır; ancak yapılan çalışmalar kadın tipi AGA'da androjen seviyelerinin anlamlı oranda artmadığını göstermiştir ${ }^{11}$. Kadın tipi AGA'nın postmenapozal kadınlarda görülmesinin daha yüksek olması östrojenin etkisini düşündürse de östrojenin kıl folikülleri üzerine etkisinin belirsiz olması nedeniyle kadın tipi AGA'lılarda daha çok kıl foliküllerine karşı artmış bir androjen duyarlılığı düşünülmektedir ${ }^{12}$.

\section{Klinik Özellikler}

Androgenetik alopesi yıllar boyunca yavaş ilerleyen bir süreçtir. İlk belirtileri ergenlik döneminde ortaya çıkabilir. Erkekte saç kaybı saçlı deri frontal bölge, verteks (M paterni) veya temporal alandan başlayabilir. Genelde hastada bir semptom olmaz, ancak bazı hastalar kaşıntı tarifleyebilir. Erkek tipi AGA'nın sınıflandırılmasında Hamilton-Norwood ölçeği kullanılır. Bu ölçek erkeklerde saç dökülmesini 7 klinik aşamada sinıflandirır ${ }^{13}$.

Kadın tipi AGA'da genellikle frontal saç çizgisi korunur, santral bölge ve vertekste dökülme olur. Bu dökülme şekli bazen değişkenlik gösterebilir, frontal bölgede daha fazla saç dökülmesi olduğunda "Noel ağacı benzeri” bir dökülme meydana gelebilir ${ }^{14}$. Kadın tipi AGA'nın değerlendirilmesinde en sık kullanılan yöntem Ludwig ölçeğidir, bu ölçekte saç dökülmesi 3 klinik aşamada sınıflandırılır ${ }^{15}$. Kadın tipi AGA'nın klinik değerlendirilmesinde Sinclair ve Savin klasifikasyonları da kullanılmaktadır.

\section{İlişkili Hastalıklar}

AGA'lı kadınlarda ve tedavi arayan bireylerde benlik saygisında azalma ve psikososyal etkilenme daha belirgindir ${ }^{16}$. Androgenetik alopesi ile kardiyovasküler risk faktörlerinin ilişkili olabileceğini belirten çalışmalar mevcuttur ${ }^{17}$. Prostat kanserinin AGA ile ilişkisini inceleyen bir çalışmada özellikle vertex tipi saç dökülmesi olan kişilerde prostat kanseri riskinin arttığ1 görülmüştür ${ }^{18}$. Prospektif bir çalışmada frontal ve frontal+midverteks kellik, kel olmayan kişilerle karş1laştırıldığında anlamlı oranda kolon kanseri ile ilişkili bulunmuştur $^{19}$. Kadın tipi AGA; hiperandrojenizm, insülin direnci, hipertansiyon, diyabet ve kalp hastalıkları ilişkili olabilir ${ }^{20}$.

\section{Tanı}

Erkek tipi AGA'da tanı genellikle fizik muayene ve hikaye ile kolay bir şekilde koyulur. Hastanın hikayesinde saç dökülmesinin saçlı derinin hangi bölgelerinden başladığı ve hastanın ailesindeki saç dökülme 


\section{Androgenetik Alopesi}

hikayesi sorgulanmalıdır. Dermatoskopik inceleme özellikle foliküler minyatürizasyonu değerlendirmek için faydalıdır. Ayrıca dermatoskopi ile kıl çaplarında farklılıklar, perifoliküler pigmentasyon/peripilar işareti ve sarı noktalar görülebilir ${ }^{21}$. Eğer tanıda şüphe duyuluyorsa biyopsi alınabilir.

Kadın tipi AGA tanısında da hasta hikayesi alınmal ve fizik muayene yapılmalıdır, dermatoskopi ve gerekiyorsa biyopsi yararlıdır. Erkek tipi AGA'ya ek olarak kadın tipi AGA'da hiperandrojenizm bulgularının (hirsutizm, ses kalınlaşması, tedaviye dirençli erişkin aknesi gibi) varlığı, jinekolojik ve obstetrik geçmiş sorgulanmalıdır. Hiperandrojenizm bulguları varlığında hastada tarama testi olarak serbest ve/veya total testesteron, dehidroepiandrosteron sülfat (DHEAS) ve 17-OH progesteron seviyelerine bakilir. Testosteron normal seviyesinin 2,5 katından veya $200 \mathrm{ng} / \mathrm{dL}$ 'den büyükse veya DHEAS premenopozal dönemde normal değerinin 2 katından veya $700 \mathrm{ug} / \mathrm{dL}$ 'den büyükse veya menopoz sonrası kadınlarda $400 \mathrm{ug} / \mathrm{dL}$ 'den büyükse tümör araştırma için görüntüleme yöntemleri kullanılmalıdır. 21-hidroksilaz eksikliğini belirleyebilmek için menstruel siklusun foliküler fazında 17$\mathrm{OH}$ progesteron düzeyi ölçümü yapılabilir. Serbest testesteron veya total testesteron düzeyi yüksekse veya galaktore varsa serum prolaktin düzeyi ölçülmelidir² ${ }^{22}$.

\section{Histopatoloji}

AGA'da tanı için genellikle histopatolojik incelemeye gerek yoktur. Tanıda şüphe varsa ve eşlik edebilen diğer saçlı deri hastalıklarını tanımlayabilmek için biyopsi alınabilir. AGA'da kadın ve erkekte biyopsi bulguları benzerdir. Biyopside horizantal kesitte bulgular daha net olarak görülebilir. Klinik bulguların derecesine bağlı olarak dermiste vellus ve vellus benzeri kıllar (çapları 0,03 mm'den küçük) görülürken, terminal kıllar (çapları 0,06 mm'den büyük) daha çok retiküler dermistedir. AGA'da anagen telogen oranı 12/1'den 5/1'e, terminal k1l vellus k1l1 oran1 7/1'den 2,5/1'e düşmüştür. Vertikal kesitlerde ise retiküler dermiste başlayıp vellüs kıllarına doğru uzanan dikey bağ dokusu sütunları görülebilir ${ }^{23}$. AGA'da biyopside inflamasyon da görülebilir, inflamasyonun foliküler minyatürizasyona neden olabileceği düşünülmektedir. İnflamasyon görülen erkek tipi AGA'lı hastalarda minoksilden fayda görme oranının inflamasyon olmayan hastalara göre daha az olduğu gösterilmiştir ${ }^{24}$.

\section{Ayırıcı Tanı}

AGA'da ayırıcı tanıda erkekte ve kadında alopesi areata, traksiyon alopesisi, skatrisyel alopesiler, trikotillomani ve telogen effluvium düşünülebilir. Özellikle kronik telogen effluviumu kadın tipi AGA'dan ayırt etmek klinik olarak zor olabilmektedir. Hasta hikayesi bize bu konuda önemli ipuçları verebilmektedir. Son zamanlarda geçirilmiş ağır hastalık, psikolojik travma, kilo kaybı, gebelik ve bazı ilaçların (doğum kontrol hapı gibi) kullanımı telogen effluviumu daha çok akla getirir.

\section{Tedavi}

AGA tedavisinde amaç foliküler minyatürizasyonu durdurmak ve saç dansitesini iyileştirmektir. Tedaviye başlamadan önce hastalara tedavilerin olası etki, yan etki ve maliyetleri hakkında bilgi verilmelidir. Hastanın tedavilerden beklentisi iyi sorgulanmalı, yeni saç çıkımı olmasa da saç dökülmesinin durmasının bile tedaviye iyi cevap olarak değerlendirileceği hasta ile paylaşılmalıdır. Hasta fayda görmediğini düşündüğü tedaviyi kullanmak istemeyebileceğinden; tedavi öncesi hastanın fotoğrafları çekilmeli, tedavi sonrasında karşılaştırma yaparken hastaya objektif kanıtlar sunulabilmelidir.

\section{Potasyum iyon kanalı düzenleyicileri}

- Topikal minoksidil

Minoksidil potasyum iyon kanalı düzenleyicisidir. Minoksidil sulfotransferaz enzimi ile aktif metaboliti olan minoksidil sülfata dönüşür. Minoksidil tedavisine yanıtların kişisel farklılık göstermesi sulfotransferaz enzim seviyelerinin bireysel farklılık göstermesinden kaynaklanabilir $^{25}$. Minoksidil vazodilatördür ve minoksidilin vasküler endotelyal büyüme faktörü (VEGF) indüksiyonu ile dermal papilların vaskülaritesini arttırdı ğı ve boyutlarını korumaya/arttırmaya yardımcı olduğu düşünülmektedir ${ }^{26}$. Bu durumun anagen evrenin uzamasını, telogen evrenin kısalmasını ve minyatürleşmiş kılların terminal kıllara dönüşmesini sağladığı düşünülmektedir.

Minoksidil spreyin \%2 ve 5'lik solüsyon ve \%5'lik köpük formu vardır. \%2'lik solüsyonu ve \%5'lik köpük formunun hem kadın hem erkek AGA tedavisinde, $\% 5$ 'lik solüsyon ve köpük formlarının ise erkek AGA tedavisinde FDA tarafindan onayı mevcuttur. Köpük formunun propilen glikol içermediği için solüsyon formuna göre daha az deri irritasyonu yaptığ 1 düşünülmektedir ${ }^{27}$.

Erkek tipi AGA tedavisinde minoksidilin \%2 ve $\% 5$ 'lik formlarının plaseboya, $\% 5$ 'lik formun $\% 2$ 'lik forma üstünlüğü gösterilmiştir ${ }^{28}$. \%5'lik solüsyon ve köpük formlarının etkinliklerinin benzer olduğu düşünülmektedir, ancak karşılaştırmalı çalışma yoktur.

Kadın tipi AGA tedavisinde minoksidil formlarının plaseboya göre etkili olduğuna dair veriler mevcuttur $^{29,30}$. Klinisyenler kadınlara \%5'lik formun \%2'lik formdan daha etkili olduğunu düşünerek $\% 5^{\prime}$ lik formu 
önerse de yapılan çalışmalar etkinliklerinin benzer olduğunu göstermektedir ${ }^{29}$.

Erkek tipi AGA'da minoksidil solüsyon ve köpük formun kuru saçlı deriye sabah akşam uygulanması önerilir. Kadın tipi AGA'da ise \%2'lik solüsyonun günde iki kez, \%5'lik solüsyon ve köpüğün günde bir kez kullanılması önerilebilir. Saç dökülmesi tedavinin ilk 2 ayında olur ve zamanla azalır. İlk yanıtı en az 4 ay sonra değerlendirmek gereklidir. Tedavi etkinliğini belirlemek için önerilen süre yaklaşık 1 yıldır.

Topikal minoksidil tedavisinde görülebilecek yan etkiler; kontakt dermatit ve hipertrikozdur. Hipertrikoz etkisi tedavi kesildikten 4 ay sonra geriler ${ }^{22}$. Uygulanan deri yüzeyinin bütünlüğünde sorun yoksa minoksidilin sistemik emilimine bağlı kardiyovasküler yan etki gelişmesi beklenmez. Minoksidilin gebelikte kullanılması önerilmez.

- Oral minoksidil

Androgenetik alopesi tedavisinde oral minoksidil kullanımı ile saç dansitesinde gelişme beklenmekle birlikte postural hipotansiyon, siv1 retansiyonu ve hipertrikozis yan etkilerinden ötürü tercih edilmemektedir. Kadın tipi AGA tedavisinde $1 \mathrm{mg} /$ gün minoksidil oral ile minoksidil sprey \%5'liği karşılaştıran 52 hasta ile yapılan randomize kontrollü bir çalışmada hipertrikoz oral minoksidil grubunda fazla görülmüş, ancak bu yan etkinin hafif olduğu ve iyi tolere edildiği belirtilmiş. Taşikardi az da olsa oral minoksidil grubunda görülürken hipotansiyon bildirilmemiş. Hastaların hiçbirisi yan etkilerden dolayı tedaviyi bırakmamış. Oral minoksidil ile topikal minoksidilin etkinlikleri benzer bulunurken, topikal minoksidil kullanamayan/tolere edemeyen kişilerde oral minoksidil 1 mg/gün dozunda kullanılabileceği önerilmiştir ${ }^{31}$.

\section{$5 \alpha$ redüktaz inhibitörleri}

\section{- Oral Finasterid}

Finasterid $5 \alpha$ redüktaz tip 2 enziminin inhibitörüdür, testesteronun dihidrotestesterona dönüşümünü inhibe eder. Erkeklerde finasteridin $1 \mathrm{mg} /$ gün dozunda oral kullanımının saç dökülmesini yavaşlattığı, saç büyümesini arttırdığı ve saç görünümünü iyileştirdiği gösterilmiştir $^{32}$. Finasterid kullanan hastaların \%90'ında saç dökülmesi durur, \%65’inde yeni saç büyümesi gözlenir ${ }^{6}$. Finasterid tedavisinin etkinliğini değerlendirebilmek için en az 12 ay, ilaç etkinliğinin devam edebilmesi için sürekli kullanılmalıdır.

Kadın tipi AGA tedavisinde finasterid kullanımı ile ilgili veriler değişiklik göstermektedir. Androgenetik alopesisi bulunan postmenopozal kadınlarda $1 \mathrm{mg} /$ gün dozunda finasteridin etkisiz olduğunu belirten çalışmalar olduğu gibi 2,5-5 mg/gün dozlarda hiperandrojenizmi olmayan kadınlarda etkili olduğunu gösteren çalışmalar da mevcuttur ${ }^{33-35}$. Oral finasteridi kadın tipi AGA tedavisinde önerebilmek için daha geniş randomize kontrollü çalışmalara ihtiyaç vardır. Finasterid teratojeniktir, erkek fetusta feminizan bulgulara neden olabilir bu nedenle doğurganlık çağındaki kadınlarda kullanılmaması veya uygun kontrasepsiyon yöntemleri ile birlikte kullanımı önerilir; fakat erkeklerde semene geçişi az olduğundan erkek kontrasepsiyonu önerilmez.

Oral finasterid tedavisinin erektil sorunlar, azalmış libido, ejakulatuar disfonksiyon, sperm sayısında azalma gibi yan etkileri bulunmaktadır, bu etkilerin geri dönüşümlü yan etkiler olduğu düşünülmektedir ${ }^{36}$. Ancak bazı hastalarda kalıcı cinsel fonksiyon bozukluğuna neden olabileceğini iddia eden çalışmalar da bulunmaktadır ${ }^{37}$. Ayrıca jinekomasti, testis ağrısı ve depresyona (daha çok $5 \mathrm{mg} /$ gün dozunda) da yol açabilir $^{38}$.

Finasterid serum prostat spesifik antijen (PSA) düzeylerini etkileyebilir. Bu yüzden tedaviye başlamadan önce bazal PSA seviyesi görülmeli veya finasterid kullanan hastalarda bu durum gözönünde bulundurularak hesaplama yapılmalıdır. Çalışmalarda prostat kanseri riskini azalttığı bulunsa da yüksek dereceli prostat kanseri riskini arttırabileceğine dair bilgiler de mevcuttur $^{39}$. Finasterid karaciğerde metabolize edilir. Bu nedenle karaciğer yetmezliği olan kişilerde dikkatli kullanılmalıdır. Finasterid erkek meme kanseri riski ile ilişkili bulunmamıştır, hatta erkeklerde ve postmenopozal kadınlarda meme kanserinden koruyucu olabileceği düşünülmektedir ${ }^{40,41}$.

\section{- Topikal finasterid}

Topikal \%1 finasterid jel ile $1 \mathrm{mg}$ /gün finasterid tabletin etkinliğinin karşılaştırıldığı 45 hastanın olduğu randomize çift kör bir klinik çalışmada 6 ay sonunda iki tedavinin etkinliklerinin benzer olduğu bulunmuş$\operatorname{tur}^{42}$. Topikal finasterid kullanımının yan etkileri ile ilgili yeterli veri yoktur.

\section{- Oral dutasterid}

Dutasterid $5 \alpha$ reduktaz izoenzim 1 ve 2 'nin inhibitörüdür. Benign prostat hiperplazisi tedavisinde 0.5 $\mathrm{mg} /$ gün dozunda kullanılmaktadır. Dutasterid ile yapılan çalışmalar finasteride göre daha azdır. Erkek tipi AGA yönetiminde 2,5 mg/gün (yüksek doz) dutasterid tedavisinin finasterid $1 \mathrm{mg} /$ gün tedavisine, 0,5 mg/gün dutasteridin ise plaseboya üstünlüğünü gösteren çalışmalar vardır ${ }^{43,44}$.

Kadın tipi AGA tedavisinde topikal minoksidil ve oral finasterid tedavisine yanıtsız bir hastada oral dutasteridin etkili olduğuna dair vaka çalışması bulunmakta$\mathrm{d}_{10}{ }^{45}$.

Dutasteridin yan etki profili finasterid ile benzerdir.

\section{Androjen reseptör antagonistleri}

\section{- Spironolakton}

Spironolakton bir aldosteron antogonisti olmakla birlikte; androjen reseptörlerini kompetitif inhibisyona uğratırken aynı zamanda androjen sentezini zayıf bir 


\section{Androgenetik Alopesi}

şekilde inhibe eder ${ }^{46}$. Spironolakton tedavisinin kadın tipi AGA tedavisinde etkili olduğuna dair retrospektif çalışmalar ve vaka çalışmaları mevcuttur ${ }^{47,48}$. Spironolakton $50 \mathrm{mg} /$ gün dozunda başlanıp doz tolere edildikçe arttırılarak 200 mg/güne kadar çıkılabilir. Spironolaktonun etkinliğini değerlendirebilmek için en az altı ay kullanılmalıdır ${ }^{49}$. Spironolaktonun yan etkileri baş ağrısı, libido azalması, adet düzensizliği, ortostatik hipotansiyon, hiperkalemi ve halsizliktir. Erkek fetusta feminizasyona neden olabileceği için gebelikte kullanılmaz. Premenapozal dönemde kullanılan bazı oral kontraseptiflerin içeriğinde bulunur.

- Siproteron asetat

Siproteron asetat gonadotropin serbestleştirici hormonu inhibe, androjen reseptörlerini bloke eder. Bir çalişmada minoksidil \%2 spreyin hiperandrojenizm bulguları olmayan kadınlarda, siproteron asetatın ise hiperandrojenizm bulgusu olan kadınlarda daha etkili olduğu gösterilmiştir ${ }^{50}$. Siproteron asetatın önerilen dozları değişiklik gösterebilmektedir, menstruel siklusun 5-15. günlerinde $100 \mathrm{mg} /$ gün siproteron asetat ve 5-25. günlerinde $50 \mathrm{mcg}$ etinil östrodiol ile kombine olarak kullanımı etkili olabilir ${ }^{51}$. Siproteron asetat kullanımında yan etki olarak menstruel düzensizlik, memede hassasiyet, kilo alımı, libido azalması ve depresyon görülebilir.

\section{- Flutamid}

Flutamid kadın tipi AGA tedavisinde nadiren kullanılan bir antiandrojendir. Prospektif bir kohort çalışmasında flutamidin hem tek başına hem de oral kontraseptiflerle birlikte kadın tipi AGA tedavisinde kullanımının (4 yıllık kohort çalışması, ilk yıl $250 \mathrm{mg} /$ gün, 2. yıl $125 \mathrm{mg} /$ gün, 3. ve 4. y1l $62,5 \mathrm{mg} /$ gün dozunda) 12. ay sonunda etkili olduğu, maksimum etkisinin 2 . yılda ortaya çıktığ 1 ve takip eden 2 yılda da ortaya çıkan bu etkinin korunduğu gösterilmiştir. Fludamide bağlı yan etkiler libido azalması, gastrointestinal sorunlar ve karaciğer fonksiyon testleri anormallikleri olarak not edilmiştir. Tedavinin ilk yılında hastaların \%4'ü ilaca bağlı karaciğer hastalıkları nedeni ile çalışmayı bırakırken, diğer yıllarda düşük doz tedavi ile çalışmayı bırakan hasta olmamıştır ${ }^{52}$.

- Korteksolon 17 alfa propionat

Korteksolon 17 alfa propionat (CB-03-01) \%5 solüsyonu AGA ve akne gibi androjen kaynaklı hastalıkların tedavisinde topikal bir ilaç olarak üretilen sentetik bir androjen reseptör antagonistidir. Erkek tipi AGA tedavisinde plasebodan üstün, \%5'lik topikal minoksidilden daha az yararlı olduğu düşünülmektedir ${ }^{53}$. İdeal doz ve kullanım süresi ile ilgili faz çalışmaları devam etmektedir.

- Topikal fluridil

Fluridil androjen reseptörünü baskılayan topikal antiandrojendir. Erkek tipi AGA tedavisinde plaseboya göre etkili olduğu gösterilmiş, sistemik emilimi olmadığı düşünülmekte, tahriş yan etkisi de bulunmamaktadir ${ }^{54}$.

\section{Diğer medikal tedaviler}

- Topikal prostoglandin analogları

Topikal latanoprost ve bimatoprost prostoglandin F2 analoglarıdır, anagen fazı uzatarak saçın büyümesini stimule ettikleri düşünülmektedir ${ }^{55}$. Latanoprost erkek tipi AGA tedavisinde plaseboya göre etkili bulunmuştur $^{56}$. Topikal bimatoprostun kadın tipi AGA tedavisinde etkisiz olduğunu bildiren çalışmalar olduğu gibi, hem erkek hem kadın tipi AGA tedavisinde etkili olabileceğini söyleyen faz çalışmaları da mevcuttur $^{53,57}$.

Androgenetik alopesi patogenezinde PD2'nin rolü olabileceği düşünülmektedir. PD2'nin reseptörüne (GPR44) bağlanması inhibe edilirse saç dökülmesinin azalacağı düşünülmüştür ve oral GPR44 antagonisti setipiprant bu amaçla çalışılan potansiyel bir tedavi ajanıdır ${ }^{53}$.

\section{- Topikal ketokonazol}

Ketokonazol ergosterol sentezini inhibe eden imidazol derivesi bir antifungaldir. Sitokrom p450 inhibisyonu yaparak adrenal bezdeki steroid sentezini azaltabilir. Saçlı derideki malessesia türlerinin neden olabileceği inflamasyonu azalttı̆̆ 1 , k1l yoğunluğunu ve kıl şaftının çapını arttırdığı, erkek tipi AGA tedavisinde etkili olabileceği bildirilmiştir ${ }^{58}$.

- Topikal melatonin

Melatonin epifiz bezinden salgılanan bir nörohormondur. İnsanlarda melatoninin saç büyümesini arttıran potent bir antioksidan olduğu düşünülmektedir. Topikal melatonin hem erkek hem kadın tipi AGA tedavisinde etkili olabilir ${ }^{59}$.

- Wnt/ $\beta$ katenin sinyal yolağı aktivatörleri

SM04554 saç büyümesininde rolü olduğu bilinen WNT yolağını etkinleştiren küçük bir moleküldür. SM04554 ile yapılan faz çalışmalarında SM04554'ün saç büyümesini ve folikül oluşumunu destekleyebileceğini düşündüren bulgular mevcuttur ${ }^{51}$. Topikal valproik asitin WNT/ $\beta$ katenin yolağ 1 aktivasyonu yaptığ1 düşünülerek gerçekleştirilen randomize çift kör plasebo kontrollü bir çalışmada topikal valproik asit ile tedavide plaseboya göre toplam saç sayısında anlamlı oranda artış saptanmıştır ${ }^{60}$. Bir başka çalışmada ise WNT7a protein, epidermal büyüme faktörleri ve folistatin içeren bir karışımın $1 \mathrm{kez}$ uygulanmasıyla saç kalınlığında ve terminal kıl dansitesinde artış olduğu, bu artışın 1 yıl sonra bile gözlendiği kaydedilmiştir ${ }^{61}$.

- JAK-STAT yolağı inhibitörleri

JAK-STAT yolağının inhibisyonu ile telogen evredeki saçların anagen evreye geçişinin hızlanabildiği gösterilmiştir ${ }^{62}$. AGA'da da saçların telogen evrede durmasindan dolayı erkek ve kadın tipi AGA tedavisinde etkili olabileceği düşünülen topikal JAK $1 / 3$ inhibitörü ATI-50002'nin faz çalışmasının sonuçları beklenmektedir $^{53}$ 


\section{Fiziksel tedaviler}

- Düşük dereceli lazer 1ş1k tedavisi

Androgenetik alopesi tedavisinde düşük dereceli lazer 1şık tedavisi (Low Level Laser Light Therapy-LLLT) de kullanılabilmektedir. LLLT'de biyokimyasal mekanizmalar tam olarak anlaşılamamıştır; ancak muhtemelen mitokondrinin hücresel solunum zincirinin 1şık enerjisini emdiği, bu durumun artan elektron taşınmasını, hücresel sinyallenmenin desteklenmesini ve saçların yeniden büyümesini sağladığı düşünülmektedir ${ }^{51}$. Hem kadın hem erkek tipi AGA tedavisinde etkin olduğunu gösteren bilgiler mevcuttur ${ }^{60} .655 \mathrm{~nm}$ dalga boyuna sahip, el tipi, non invaziv bir cihaz olan Hair Max LaserComb (Lexington International, LLC, Boca Raton, FL) FDA tarafindan kadın ve erkek tipi AGA tedavisinde onaylıdır ${ }^{51}$. Haftada 3 gün 20 dakika olarak kullanılabilir.

\section{- Lazer tedavileri}

Kılların diod lazer ile epilasyonu sirasında, lazer yap1lan alanların bitişiğindeki dokularda paradoksal hipertrikozis görülebilmektedir. Lazer tedavilerinin uyku halindeki kıl foliküllerini aktive edebileceği, kan akımını arttırabileceği ve büyüme faktörlerinin üretimini indükleyebileceği düşünülmektedir ${ }^{64}$. Kadın tipi AGA's olan 27 hastaya 2 hafta aralıklarla 10 seans $1550 \mathrm{~nm}$ fraksiyonel erbium glass lazer uygulaması yapılmış, 5 ay sonunda saç yoğunluğunda ve ortalama saç kalınlığında anlamlı bir artış gözlenmiş ${ }^{65}$. Yan etki olarak hafif eritem ve kaşıntı bildirilmiş. AGA yönetiminde lazer tedavisinin hangi aralıklarla ve hangi parametrelerle önerilebileceğine dair daha fazla çalışma gereklidir.

\section{- Mikroiğneleme}

Mikroiğneleme yöntemi bir roller yardımıyla ince iğnelerin stratum korneumda delik açtığı minimal invaziv bir dermatolojik prosedürdür. Mikroiğneleme yöntemi ile tedavi edilen alanlarda kollajen oluşumu, neovaskülarizasyon ve büyüme faktörü üretimi indüklenir. Literatürde etkinliğini değerlendiren çalışmalar sınırlı sayıdadır. Alopesi areata ve androgenetik alopeside kullanımı mevcuttur. Topikal minoksidil, PRP ve topikal steroidlerle birlikte kullanılabilir. Mikroiğneleme yöntemi ile bu tür ilaçların penetrasyonunun arttığı düşünülmektedir. Ayrıca PDGF (platelet derived growth factor) ve epidermal büyüme faktörü miktarını arttırdığı düşünülmekte ve bazı kıl büyümesiyle ilgili genlerin (beta-katenin, Wnt3a, Wnt10b) ekspresyonunu arttırarak etkili olduğu öne sürülmektedir ${ }^{66}$.

\section{- Mezoterapi}

Mezoterapi son zamanlarda genellikle kozmetik alanda (saç dökülmesi, hiperpigmentasyon, stria, selülit, deri gençleştirme gibi) kullanılan çeşitli karışımların deri altına enjekte edilmesine verilen isimdir. Androgenetik alopeside finasterid ve minoksidilin yanısıra vazodilatörler, doğal bitki özleri ve vitamin içeren karışımlar kullanılır. Mezoterapinin AGA'da kullanımını destekleyen yeterli klinik çalışma yoktur ${ }^{67}$.

\section{- Platelet zengin plazma (PRP)}

PRP hastanın kendi plazması santrifüj edilerek elde edilir. Plateletler mezenkimal hücrelerin, fibroblastların, osteoblastların ve endotelyal hücrelerin çoğalmasını ve kök hücrelerin proliferasyonunu uyarabilen çok sayıda büyüme faktörü içerir. PRP içerdiği büyüme faktörleri sayesinde pek çok alanda kullanılabilmektedir. PRP tedavisi kıl kökündeki kök hücrelerin diferansiyasyonunu indükleyen beta katenin ekspresyonunu, anagen fazı uzatan fibroblast büyüme faktörünü ve hücreleri apoptozisten kurtaran Bcl-2'yi arttırabilir. Kadın ve erkek AGA tedavisinde PRP uygulanımı çalışmalarda denenmiş, çelişkili sonuçlar ortaya çıkmıştır. Kadın ve erkek AGA tedavisinde 25 hastada ayda bir 3 kez PRP tedavisi uygulanmış, hastalar ilk tedaviden 6 ay sonra önceki halleriyle karşılaştırılmış; anagen saçlarda ve terminal saç dansitesinde anlamlı oranda artış saptanmıştır ${ }^{68}$. Erkek tipi AGA tedavisinde 1 ay arayla 2 kez uygulanan PRP tedavisi ile plasebonun 17 hastada karşılaştırıldığ PRP'nin plaseboya üstünlüğü gösterilememiştir ${ }^{69}$. Saç transplantasyonu öncesi ve sonrası transplante edilecek/edilen alana PRP uygulanması ve ekilecek saçların ekilene kadar PRP içeren ürünlerde saklanmasını öneren yayınlar da mevcuttur ${ }^{70}$. PRP'nin AGA tedavisinde etkinliğini değerlendirebilmek için daha geniş çaplı randomize kontrollü çalışmalar gereklidir.

\section{- Kök hücre tedavileri}

Adipoz doku VEGF, hepatosit büyüme faktörü, insülin benzeri büyüme faktörleri gibi büyüme faktörlerini üretebilen mezenkimal kök hücreler açısından zengindir. Kadın tipi AGA'sı bulunan 27 hastaya mikroiğneleme sonrası adipoz doku kaynaklı kök hücreler (Adipose-derived stem cells-ADSCs) haftada bir uygulanmış, 12 hafta sonunda saç dansitesinde ve saç kalınlığında anlamlı bir artış bulunmuştur ${ }^{71}$. Bir başka çalışmada ise 16 erkek, 5 kadın AGA'lı hastada ADSCs tedavisi ile başlangıca göre saç sayısında artış olduğu gösterilmiştir ${ }^{72}$.

\section{Tamamlayıcı Tedaviler}

\section{- Saç transplantasyonu}

Saç dökülmesi için kalıcı iyileşme isteyen, stabil veya tıbbi olarak kontrol edilen androgenetik alopesisi olan hastalar yeterli saç rezervuarına sahipse saç transplantasyonu düşünülebilir. Ekim için donör alınan yer genellikle saç dökülmesine dirençli oksipital alandır, saç ekimi yapıldığında saç oksipital bölgedeki özelliklerini korur.

Saç transplantasyonunda genel olarak iki teknik kullanılmaktadır. Foliküler ünite transplantasyonu (FUT) tekniğinde lokal anestezi altında 8-15 mm genişliğinde 


\section{Androgenetik Alopesi}

20-30 cm uzunluğunda deri parçası oksipital bölgeden cerrahi olarak eksize edilir. Foliküler üniteler mikroskoplar yardımıyla doku şeridinden dikkatlice diseke edilir ve ardından androgenetik alopesi alanlarına nakledilir. Foliküler ünite ekstraksiyonunda (FUE) ise oksipital alandan foliküler üniteler tek tek çıkarılır. Bu yöntem ile oksipital alanda çizgi şeklinde skatris kalmaz. FUE tekniği bu yüzden daha uzun zaman almaktadır. Standart bir saç ekimi seansı 5-8 saat arası sürer. Saç ekimi sonrası topikal minoksidil, finasterid tb ve/veya PRP ile saç desteklenmesine devam edilmesi genellikle önerilir. Androgenetik alopesisi olan 79 erkek ile yapılan bir çalışmada nakilden 4 hafta önce ve nakil sonrası 48 hafta boyunca $1 \mathrm{mg} /$ gün finasterid tb kullanan hastalardaki sonuçların daha iyi olduğu gösterilmiştir ${ }^{73}$. Kadın tipi AGA tedavisinde de medikal tedaviye dirençli hastalarda saç transplantasyon yöntemi kullanılabilir ${ }^{74}$. Yüksek maliyet, tedavi seanslarının uzun sürmesi, tedavi sonrası ağrı ve enfeksiyon görülebilmesi saç transplantasyonunun olası yan etkileridir.

\section{- Besin takviyeleri}

Androgenetik alopesi tedavisinde aminoasit, biotin, çinko gibi besin takviyelerinin yeri tartışmalıdır ${ }^{51}$.

- Kamuflaj yöntemi

Saça serpilen keratin lifleri, saç derisi renklendiricileri, kaynak saç, peruk, bandana ve şapka kamuflaj ürünleri olarak hastalara önerilebilir ${ }^{64}$.

\section{Kombinasyon tedavileri}

Androgenetik alopesisi olan 100 hasta ile yapılan bir çalışmada tedavilerin etkinlik sıralaması oral finasterid+topikal minoksidil kombinasyon tedavisi, oral finasterid+topikal ketokonazol, oral finasterid, topikal minoksidil olduğu gösterilmiştir ${ }^{75}$. Farklı etki mekanizmasına sahip tedavileri kombine kullanmak androgenetik alopesi tedavisinin etkinliğini arttırabilir.

\section{Sonuç}

Kadın ve erkekte androgenetik alopesi patogenezi tam olarak aydınlatılamamıştır. Hem patogenezde hem tedavide benzerlikler olsa da farklılıklar da göz ard1 edilmemeli, her hasta ayrı değerlendirilmelidir. Onaylı tedavi seçenekleri sınırlı olsa da hastalara etkinliği kanıtlanmış tedaviler öncelikle önerilmeli, gerektiğinde tedaviler kombine edilmelidir. Günümüzdeki mevcut tedavi seçeneklerinin kesin etki mekanizmalarının bilinmesi, etkinlikleri ile ilgili çelişkilerin giderilmesi, uygulanması ile ilgili standart protokollerin geliştirilmesi ve güvenlik profillerinin tam olarak öğrenilmesi gerekmektedir.
Araştırmacı Katkı Beyanı:

Fikir ve tasarım: F.A., G.Ş.; Veri toplama ve işleme: H.Ö., F.A., G.Ş.; Analiz ve verilerin yorumlanması: G.Ş., H.Ö.; Makalenin önemli bölümlerinin yazılması: G.Ş., F.A.

Destek ve Teşekkür Beyanı:

Makale yazarlarının destek ve teşekkür beyanı yoktur.

Çıkar Çatışması Beyanı:

Makale yazarlarının çıkar çatışması beyanı yoktur.

\section{Kaynaklar}

1. Rhodes T, Girman CJ, Savin RC, et al. Prevalence of male pattern hair loss in 18-49 year old men. Dermatol Surg 1998;24(12):1330-2.

2. Norwood OT. Incidence of female androgenetic alopecia (female pattern alopecia). Dermatol Surg 2001;27(1):53-4.

3. Paik JH, Yoon JB, Sim WY, Kim BS, Kim NI. The prevalence and types of androgenetic alopecia in Korean men and women. Br J Dermatol 2001;145(1):95-9.

4. Heilmann-Heimbach S, Hochfeld LM, Paus R, Nöthen MM. Hunting the genes in male-pattern alopecia: how important are they, how close are we and what will they tell us? Exp Dermatol 2016;25(4):251-7.

5. Tosti A, Iorizzo M, Piraccini BM. Androgenetic alopecia in children: report of 20 cases. Br J Dermatol 2005;152(3):556-9.

6. Sperling LC, Sinclair RD, Shabrawi-Caelen LE: Alopecias. In Bolognia JL, Schaffer JV, Cerroni L (eds): Dermatology. Forth Edition. Elsevier, 2018. pp. 1162-87.

7. Imperato-McGinley J, Zhu YS. Androgens and male physiology the syndrome of 5alpha-reductase-2 deficiency. Mol Cell Endocrinol 2002;198(1-2):51-9.

8. Sawaya ME, Price VH. Different levels of 5alpha-reductase type I and II, aromatase, and androgen receptor in hair follicles of women and men with androgenetic alopecia. J Invest Dermatol 1997;109(3):296-300.

9. Sawaya ME. Purification of androgen receptors in human sebocytes and hair. J Invest Dermatol 1992;98(6 Suppl):92S96S.

10. Garza LA, Liu Y, Yang Z, et al. Prostaglandin D2 inhibits hair growth and is elevated in bald skalpof men with androgenetic alopecia . Sci Transl Med 2012;4:126ra34

11. Schmidt JB, Lindmaier A, Trenz A, Schurz B, Spona J. Hormone studies in females with androgenic hairloss. Gynecol Obstet Invest 1991;31(4):235-9.

12. Yip L, Rufaut N, Sinclair R. Role of genetics and sex steroid hormones in male androgenetic alopecia and female pattern hair loss: an update of what we now know. Australas J Dermatol. 2011;52(2):81-8.

13. Norwood OT. Male pattern baldness: classification and incidence. South Med J 1975;68(11):1359-65.

14. Olsen EA. Female pattern hair loss. J Am Acad Dermatol 2001;45(3 Suppl):S70-80

15. Ludwig E. Classification of the types of androgenetic alopecia (common baldness) occurring in the female sex. Br J Dermatol 1977;97(3):247-54

16. Cash TF. The psychosocial consequences of androgenetic alopecia: a review of the research literature. $\mathrm{Br} \mathrm{J}$ Dermatol 1999;141(3):398-405.

17. Arias-Santiago S, Gutiérrez-Salmerón MT, CastelloteCaballero L, Buendía-Eisman A, Naranjo-Sintes R. Androgenetic alopecia and cardiovascular risk factors in men and women: a comparative study. J Am Acad Dermatol 2010;63(3):420-9. 


\section{G. Şahin, ark.}

18. Amoretti A, Laydner H, Bergfeld W. Androgenetic alopecia and risk of prostate cancer: a systematic review and metaanalysis. J Am Acad Dermatol 2013;68(6):937-43.

19. Keum N, Cao Y, Lee DH, et al. Male pattern baldness and risk of colorectal neoplasia. Br J Cancer 2016;114(1):110-7.

20. Hirsso P, Rajala U, Laakso M, et al. Health-related quality of life and physical well-being among a 63-year-old cohort of women with androgenetic alopecia; a Finnish population-based study. Health Qual Life Outcomes 2005;3:49.

21. Inui S. Trichoscopy for common hair loss diseases: algorithmic method for diagnosis. J Dermatol 2011;38(1):71-5.

22. Olsen EA, Messenger AG, Shapiro J, et al. Evaluation and treatment of male and female pattern hair loss. J Am Acad Dermatol 2005;52(2):301-11.

23. Horenstein MG, Jacob JS. Follicular streamers (stelae) in scarring and non-scarring alopecia. J Cutan Pathol 2008;35(12):1115-20.

24. Whiting DA. Diagnostic and predictive value of horizontal sections of scalp biopsy specimens in male pattern androgenetic alopecia. J Am Acad Dermatol 1993;28:755-63.

25. Chitalia J, Dhurat R, Goren A, et al. Characterization of follicular minoxidil sulfotransferase activity in a cohort of pattern hair loss patients from the Indian Subcontinent. Dermatol Ther 2018;31(6):e12688.

26. Lachgar S, Charveron M, Gall Y, Bonafe JL. Minoxidil upregulates the expression of vascular endothelial growth factor in human hair dermal papilla cells. $\mathrm{Br} \mathrm{J}$ Dermatol 1998;138(3):407-11.

27. Olsen EA, Whiting D, Bergfeld W, et al. A multicenter, randomized, placebo-controlled, double-blind clinical trial of a novel formulation of $5 \%$ minoxidil topical foam versus placebo in the treatment of androgenetic alopecia in men. J Am Acad Dermatol 2007;57(5):767-74.

28. Olsen EA, Dunlap FE, Funicella T, et al. A randomized clinical trial of $5 \%$ topical minoxidil versus $2 \%$ topical minoxidil and placebo in the treatment of androgenetic alopecia in men. J Am Acad Dermatol 2002;47(3):377-85

29. van Zuuren EJ, Fedorowicz Z, Schoones J. Interventions for female pattern hair loss. Cochrane Database Syst Rev 2016;2016(5):CD007628.

30. Bergfeld W, Washenik K, Callender V, et al. A Phase III, Multicenter, Parallel-Design Clinical Trial to Compare the Efficacy and Safety of 5\% Minoxidil Foam Versus Vehicle in Women With Female Pattern Hair Loss. J Drugs Dermatol 2016;15(7):874-81.

31. Ramos PM, Sinclair RD, Kasprzak M, Miot HA. Minoxidil $1 \mathrm{mg}$ oral versus minoxidil 5\% topical solution for the treatment of female-pattern hair loss: A randomized clinical trial. J Am Acad Dermatol 2020;82(1):252-253.

32. Kaufman KD, Olsen EA, Whiting D, et al. Finasteride in the treatment of men with androgenetic alopecia. Finasteride Male Pattern Hair Loss Study Group. J Am Acad Dermatol 1998;39:578-89.

33. Price VH, Roberts JL, Hordinsky M, et al. Lack of efficacy of finasteride in postmenopausal women with androgenetic alopecia. J Am Acad Dermatol 2000;43:768-76.

34. Yeon JH, Jung JY, Choi JW, et al. $5 \mathrm{mg} /$ day finasteride treatment for normoandrogenic Asian women with female pattern hair loss. J Eur Acad Dermatol Venereol 2011;25(2):211-4.

35. Trüeb RM; Swiss Trichology Study Group. Finasteride treatment of patterned hair loss in normoandrogenic postmenopausal women. Dermatology 2004;209(3):202-7.

36. Mella JM, Perret MC, Manzotti M, Catalano HN, Guyatt G. Efficacy and safety of finasteride therapy for androgenetic alopecia: a systematic review. Arch Dermatol 2010;146(10):114150.
37. Irwig MS, Kolukula S. Persistent sexual side effects of finasteride for male pattern hair loss. J Sex Med 2011;8(6):1747-53.

38. Rahimi-Ardabili B, Pourandarjani R, Habibollahi P, Mualeki A. Finasteride induced depression: a prospective study. BMC Clin Pharmacol 2006;6:7.

39. Klein EA, Tangen CM, Goodman PJ, Lippman SM, Thompson IM. Assessing benefit and risk in the prevention of prostate cancer: the prostate cancer prevention trial revisited. J Clin Oncol 2005;23(30):7460-6.

40. Kjærulff TM, Ersbøll AK, Green A, et al. Finasteride Use and Risk of Male Breast Cancer: A Case-Control Study Using Individual-Level Registry Data from Denmark, Finland, and Sweden. Cancer Epidemiol Biomarkers Prev 2019;28(5):980986.

41. Lehrer S. Finasteride for postmenopausal breast cancer prevention. Eur J Cancer Prev 2015;24(5):456-7.

42. Hajheydari Z, Akbari J, Saeedi M, Shokoohi L. Comparing the therapeutic effects of finasteride gel and tablet in treatment of the androgenetic alopecia. Indian J Dermatol Venereol Leprol 2009;75(1):47-51.

43. Olsen EA, Hordinsky M, Whiting D, et al; Dutasteride Alopecia Research Team. The importance of dual 5alpha-reductase inhibition in the treatment of male pattern hair loss: results of a randomized placebo-controlled study of dutasteride versus finasteride. J Am Acad Dermatol 2006;55(6):1014-23.

44. Eun HC, Kwon OS, Yeon JH, et al. Efficacy, safety, and tolerability of dutasteride $0.5 \mathrm{mg}$ once daily in male patients with male pattern hair loss: a randomized, double-blind, placebocontrolled, phase III study. J Am Acad Dermatol 2010;63(2):252-8.

45. Olszewska M, Rudnicka L. Effective treatment of female androgenic alopecia with dutasteride. J Drugs Dermatol 2005;4(5):637-40.

46. Rathnayake D, Sinclair R. Innovative use of spironolactone as an antiandrogen in the treatment of female pattern hair loss. Dermatol Clin 2010;28(3):611-8.

47. Famenini S, Slaught C, Duan L, Goh C. Demographics of women with female pattern hair loss and the effectiveness of spironolactone therapy. J Am Acad Dermatol 2015;73(4):7056.

48. Yazdabadi A, Green J, Sinclair R. Successful treatment of female-pattern hair loss with spironolactone in a 9-year-old girl. Australas J Dermatol 2009;50(2):113-4.

49. Camacho-Martínez FM. Hair loss in women. Semin Cutan Med Surg 2009;28(1):19-32.

50. Vexiau P, Chaspoux C, Boudou P, et al. Effects of minoxidil $2 \%$ vs. cyproterone acetate treatment on female androgenetic alopecia: a controlled, 12-month randomized trial. Br J Dermatol 2002;146(6):992-9.

51. Fabbrocini G, Cantelli M, Masarà A, et al. Female pattern hair loss: A clinical, pathophysiologic, and therapeutic review. Int J Womens Dermatol 2018;4(4):203-211.

52. Paradisi R, Porcu E, Fabbri R, et al. Prospective cohort study on the effects and tolerability of flutamide in patients with female pattern hair loss. Ann Pharmacother 2011;45(4):469-75.

53. Ocampo-Garza J, Griggs J, Tosti A. New drugs under investigation for the treatment of alopecias. Expert Opin Investig Drugs 2019;28(3):275-284.

54. Sovak M, Seligson AL, Kucerova R, et al. Fluridil, a rationally designed topical agent for androgenetic alopecia: first clinical experience. Dermatol Surg 2002;28(8):678-85.

55. Valente Duarte de Sousa IC, Tosti A. New investigational drugs for androgenetic alopecia. Expert Opin Investig Drugs 2013;22(5):573-89.

56. Blume-Peytavi U, Lönnfors S, Hillmann K, Garcia Bartels N. A randomized double-blind placebo-controlled pilot study to assess the efficacy of a 24-week topical treatment by latanoprost 


\section{Androgenetik Alopesi}

$0.1 \%$ on hair growth and pigmentation in healthy volunteers with androgenetic alopecia. J Am Acad Dermatol 2012;66(5):794-800.

57. Emer JJ, Stevenson ML, Markowitz O. Novel treatment of female-pattern androgenetic alopecia with injected bimatoprost 0.03\% solution. J Drugs Dermatol 2011;10(7):795-8.

58. Piérard-Franchimont C, De Doncker P, Cauwenbergh G, Piérard GE. Ketoconazole shampoo: effect of long-term use in androgenic alopecia. Dermatology 1998;196(4):474-7.

59. Fischer TW, Trüeb RM, Hänggi G, Innocenti M, Elsner P. Topical melatonin for treatment of androgenetic alopecia. Int J Trichology 2012;4(4):236-45.

60. Jo SJ, Shin H, Park YW, et al. Topical valproic acid increases the hair count in male patients with androgenetic alopecia: a randomized, comparative, clinical feasibility study using phototrichogram analysis. J Dermatol 2014;41(4):285-91.

61. Zimber MP, Ziering C, Zeigler F, et al. Hair regrowth following a Wnt- and follistatin containing treatment: safety and efficacy in a first-in-man phase 1 clinical trial. J Drugs Dermatol 2011;10(11):1308-12.

62. Harel S, Higgins CA, Cerise JE, et al. Pharmacologic inhibition of JAK-STAT signaling promotes hair growth. Sci Adv 2015;1(9):e1500973.

63. Jimenez JJ, Wikramanayake TC, Bergfeld W, et al. Efficacy and safety of a low-level laser device in the treatment of male and female pattern hair loss: a multicenter, randomized, sham device-controlled, double-blind study. Am J Clin Dermatol 2014;15(2):115-27.

64. Kelly Y, Blanco A, Tosti A. Androgenetic Alopecia: An Update of Treatment Options. Drugs 2016;76(14):1349-64.

65. Lee GY, Lee SJ, Kim WS. The effect of a $1550 \mathrm{~nm}$ fractional erbium-glass laser in female pattern hair loss. J Eur Acad Dermatol Venereol 2011 Dec;25(12):1450-4.
66. Fertig RM, Gamret AC, Cervantes J, Tosti A. Microneedling for the treatment of hair loss? J Eur Acad Dermatol Venereol 2018;32(4):564-569.

67. Mysore V. Mesotherapy in management of hairloss - Is it of any use? Int J Trichology 2010;2(1):45-6.

68. Alves R, Grimalt R. Randomized placebo-controlled, doubleblind, half-head study to assess the efficacy of platelet-rich plasma on the treatment of androgenetic alopecia. Dermatol Surg 2016;42(4):491-7.

69. Mapar MA, Shahriari S, Haghighizadeh MH. Efficacy of platelet-rich plasma in the treatment of androgenetic (malepatterned) alopecia: A pilot randomized controlled trial. J Cosmet Laser Ther 2016;18(8):452-455.

70. Rose PT. The latest innovations in hair transplantation. Facial Plast Surg 2011;27(4):366-77.

71. Harel S, Higgins CA, Cerise JE, et al. Pharmacologic inhibition of JAK-STAT signaling promotes hair growth. Sci Adv 2015;1(9):e1500973.

72. Shin H, Ryu HH, Kwon O, Park BS, Jo SJ. Clinical use of conditioned media of adipose tissue-derived stem cells in female pattern hair loss: a retrospective case series study. Int J Dermatol 2015;54(6):730-5.

73. Leavitt M, Perez-Meza D, Rao NA, et al. Effects of finasteride (1 mg) on hair transplant. Dermatol Surg 2005;31(10):1268-76, discussion 1276.

74. Epstein JS. The treatment of female pattern hair loss and other applications of surgical hair restoration in women. Facial Plast Surg Clin North Am 2004;12(2):241-7.

75. Khandpur S, Suman M, Reddy BS. Comparative efficacy of various treatment regimens for androgenetic alopecia in men. $\mathrm{J}$ Dermatol 2002;29(8):489-98. 
